\title{
Article \\ Increasing the Adherence of Metallic Copper to the Surface of Titanium Hydride
}

\author{
Vyacheslav Ivanovich Pavlenko, Andrey Ivanovich Gorodov *, Roman Nikolayevich Yastrebinsky (), \\ Natalia Igorevna Cherkashina and Alexander Alexandrovich Karnauhov
}

\author{
Department of Theoretical and Applied Chemistry, Belgorod State Technological University Named after V.G. \\ Shukhov, 308012 Belgorod, Russia; belpavlenko@mail.ru (V.I.P.); yrndo@mail.ru (R.N.Y.); \\ natalipv13@mail.ru (N.I.C.); gamma.control@ya.ru (A.A.K.) \\ * Correspondence: gorodov-andreyy@mail.ru; Tel.: +7-4722-551662
}

Citation: Pavlenko, V.I.; Gorodov, A.I.; Yastrebinsky, R.N.; Cherkashina, N.I.; Karnauhov, A.A. Increasing the Adherence of Metallic Copper to the Surface of Titanium Hydride. ChemEngineering 2021, 5, 72. https://doi.org/10.3390/ chemengineering5040072

Academic Editor: Changhyun Roh

Received: 18 August 2021

Accepted: 21 October 2021

Published: 25 October 2021

Publisher's Note: MDPI stays neutral with regard to jurisdictional claims in published maps and institutional affiliations.

Copyright: (c) 2021 by the authors. Licensee MDPI, Basel, Switzerland. This article is an open access article distributed under the terms and conditions of the Creative Commons Attribution (CC BY) license (https:// creativecommons.org/licenses/by/ $4.0 /)$.
Abstract: Studies have been carried out to increase the adhesive interaction between a titanium hydride substrate and a copper coating. An additional layer containing chemically active groups was created on the surface of the spherical titanium hydride by chemisorption modification. This paper discusses the results of scanning electron microscopy (SEM) using energy-dispersive X-ray spectroscopic mapping of coatings obtained on spherical granules of titanium hydride before and after adsorption modification. The mechanism of interaction of the surface of spherical granules of titanium hydride and titanium sulfate salt is proposed. It is shown that the creation of a chemisorbed layer of hydroxotitanyl and the subsequent electrodeposition of metallic copper contribute to the formation of a multilayer shell of a titanium-copper coating on the surface of spherical titanium hydride granules ( $\equiv \mathrm{Ti}-\mathrm{O}-\mathrm{Cu}-$ ) with a high adhesive interaction. Results have been given for an experimental study of the thermal stability of the initial spherical granules of titanium hydride and granules coated with a multilayer titanium-copper shell.

Keywords: modifier; neutron shielding; titanium hydride; surface; sorption; scanning electron microscopy; adhesion; electrodeposition; copper; hydroxotitanyl; X-ray; adsorption; chemisorption

\section{Introduction}

In connection with the development of the nuclear industry around the world, the development of new materials for radiation protection has become a necessity. The main focus in this area is on the development of composites based on transition metal hydrides [1,2].

Metal hydrides that have temperature stability in the high-temperature range (up to $800^{\circ} \mathrm{C}$ ) are the most promising $[3,4]$. The main attention should be paid to titanium hydride $\left(\mathrm{TiH}_{2}\right)$, which contains a large number of hydrogen atoms per $1 \mathrm{~cm}^{3}$ of the metal $\left(9.2 \times 10^{22}\right)$, second only to vanadium hydride $11.4 \times 10^{22}$ [5].

Titanium hydride in the form of polydisperse crumbs is used to fill voids and gaps between radiation-protective products. The disadvantage of titanium hydride crumbs is the presence of up to $5 \%$ of the fine fraction (less than $0.2 \mathrm{~mm}$ ) in its composition. This factor is an obstacle to the widespread use of crumbs since the fine fraction is fire hazardous and explosive, and additional hydrogen is released during operation at high temperatures [6,7]. During transportation, packaging, and manufacturing of the mixture, the amount of the fine fraction may increase.

Titanium hydride in the form of spherical granules is increasingly being used in practice [8-10]. The use of spherical titanium hydride eliminates the disadvantages of using polydisperse powder. The spherical shape of the granules allows the use of titanium hydride as a filler for protective structures of complex configuration. A distinctive feature of spherical granules made of titanium hydride is that they have higher strength and explosion safety [11]. 
However, it was shown in $[5,12]$ that spherical titanium hydride has microcracks $(20-30 \mathrm{~nm})$ on its surface through which hydrogen can be thermodiffused from the surface layers and from the entire volume of the granules.

In the presence of spherical cracks on the surface of titanium hydride, the rate of its oxidation and thermal diffusion of hydrogen at $300-400{ }^{\circ} \mathrm{C}$ is about two times higher than for granules without cracks $[5,13]$. Therefore, much attention has been paid to the work aimed at obtaining spherical samples of titanium hydride in which there are no cracks or their numbers are reduced to a minimum. The analysis of the available research in this direction $[3,4,14]$ showed that the regulation of the conditions for the production (pressure and temperature conditions) of spherical titanium hydride granules does not solve the problem of the formation of surface microcracks. The most promising method is to "heal" microcracks by artificially creating a multi-barrier system of energy "traps" on the surface of the granule, which makes it possible to slow down the processes of thermal diffusion of hydrogen from the crystal lattice of titanium hydride at high temperatures and protect titanium from oxidation [5,15-25].

For example, the use of a copper coating to create a multi-barrier system of energy "traps" on the surface of titanium hydride spheres increases their thermal stability by creating a protective shell that prevents the thermal diffusion of hydrogen into the environment. In the literature, there are many works on the creation of a copper layer, such as electrophoretic deposition [26], continuous casting [27], reactive DC magnetron sputtering [28], dip coating [29], and others [30-34]. The copper layer completely covers the surface of the spherical titanium hydride, covering all surface microcracks. However, in the literature [35-38], a weak adhesive interaction between the titanium and copper layers is noted.

The aim of this work is to improve the adherence of the copper coating to the surface of spherical titanium hydride granules and to prevent its detachment. To achieve this goal, studies were conducted to create an additional layer containing chemically active groups on the surface of titanium hydride in a spherical shape by chemisorption modification. It was assumed that this approach would "heal" defects and microcracks of the surface of titanium hydride granules with simultaneous activation of the surface for subsequent electrochemical deposition of copper ions.

\section{Materials and Methods}

As an object of research, titanium hydride granules of spherical shape (diameter 0.2-2.5 mm) of non-stoichiometric composition $\mathrm{TiH}_{1.7}$ were used in the work.

To obtain a solution of titanium sulfate salt, titanium plates were previously dissolved in hot concentrated sulfuric acid. The equation of the reaction between concentrated sulfuric acid and titanium metal under the action of temperature is as follows:

$$
2 \mathrm{Ti}+6 \mathrm{H}_{2} \mathrm{SO}_{4} \stackrel{\mathrm{t}}{\rightarrow} \mathrm{Ti}_{2}\left(\mathrm{SO}_{4}\right)_{3}+3 \mathrm{SO}_{2} \uparrow+6 \mathrm{H}_{2} \mathrm{O}
$$

During the reaction, crystallohydrates of acid salts $\mathrm{Ti}_{2} \mathrm{H}_{4}\left(\mathrm{SO}_{4}\right)_{5} \cdot 3 \mathrm{H}_{2} \mathrm{O}$ (blue precipitate) and $\mathrm{TiH}\left(\mathrm{SO}_{4}\right)_{2} \cdot 4 \mathrm{H}_{2} \mathrm{O}$ (in the form of a purple colloidal solution) were obtained. The resulting compounds were used for subsequent modification of the surface of the titanium hydride fraction.

Strongly acidic solutions (at $\mathrm{pH}=1$ ) contain mainly $\mathrm{TiO}^{2+}$ ions in their composition. When the $\mathrm{pH}$ values increase, titanium (IV) ions undergo hydrolysis to form poorly soluble compounds. It is worth noting that the process of hydrolysis of titanium (IV) ions begins already at $\mathrm{pH} \geq 1.5$. In the range of values $\mathrm{pH}=1.5-2$, the hydrolysis form of the composition $\mathrm{Ti}(\mathrm{OH})_{2}{ }^{2+}$ prevails in solutions. Further hydrolysis of $\mathrm{Ti}(\mathrm{OH})_{2}{ }^{2+}$ at values $\mathrm{pH}=4-5$ leads to the accumulation of $\left[\mathrm{Ti}\left(\mathrm{H}_{2} \mathrm{O}\right)_{6}\right]^{4+}$ ions in the solution. During the hydrolysis of titanium (IV) ions in acidic solutions, mononuclear large molecules are mainly formed, although the possibility of higher-order forms is not excluded. 
To increase the efficiency of sorption of titanium compounds on the $\mathrm{TiH}_{2}$ surface, the $\mathrm{pH}$ of titanium sulfate salts was increased to $\mathrm{pH}=4-5$ by adding $\mathrm{NH}_{4} \mathrm{OH}$, followed by passing the resulting solution through a column filled with spherical titanium hydride.

After the termination of the adsorption contact, spherical granules of titanium hydride were thoroughly washed with distilled water. To remove the crystallization water, the granules were dried at a temperature of $180^{\circ} \mathrm{C}$.

The obtained coatings were examined by scanning electron microscopy (SEM) using energy dispersive X-ray spectroscopy (EDS) mapping. The study was carried out on a TESCAN MIRA 3LMU high-resolution scanning electron microscope (manufacturer TESCAN ORSAY HOLDING, Brno, Czech Republic). The survey was carried out in the mode of secondary electrons.

The topography of the surface structures of spherical titanium hydride was studied using an NTEGRA Aura high-resolution scanning probe microscope (manufacturer NT-MDT, Moscow, Russia). To scan topographic images, we used stable and indestructible, moistureresistant AFM cantilevers coated with doped diamond for long-term measurements (manufacturer NT-MDT, Russia). The intermittent contact mode of the HA_HR_HDCP (High Accuracy High Resonance) series with a resonant frequency of $250 \mathrm{kHz}$ and a power constant of $17 \mathrm{~N} / \mathrm{m}$ was used for operation. The processing of SPM images was carried out using a special image analysis program. The indicator of the arithmetic mean roughness Ra is determined, based on the calculation of the average height differences over a surface of a given size.

To create an additional protective shell, electrochemical deposition of copper ions from an aqueous solution of its salt on the surface of a spherical titanium hydride was carried out. Electroplating of copper was carried out on the IPC-Pro 3A potentiostat installation in a vessel filled with a $30 \%$ aqueous solution of copper sulfate $\left(\mathrm{CuSO}_{4} \cdot 5 \mathrm{H}_{2} \mathrm{O}\right)$. A copper plate was used as the anode. The cathode consisted of spherical granules of titanium hydride, which fit tightly to steel rods previously cleaned from the oxide film. To ensure tight contact of spherical titanium hydride with the surface of steel electrodes, they were placed in a perforated polymer cylindrical container. Electroplating was carried out at a current density of $1.5-2 \mathrm{~A} / \mathrm{dm}^{2}$ and a process time of $10 \mathrm{~min}$. The control of the applied coatings was carried out by optical and scanning electron microscopy.

Differential thermal (DTA), thermogravimetric (TG), and differential thermogravimetric (DTG) analysis of the samples were performed on an STA-449 F1 Iupiter (Germany). Thermogravimetric methods of analysis allow us to continuously record the change in the mass of the sample with a high degree of accuracy to analyze the physical, chemical, or physico-chemical processes occurring in the substance under the influence of temperature. With the help of the DTG curve, it is possible to separate the overlapping thermal effects that are not separable in the DTA curves. The peaks on the DTG curves correspond to the maximum rate of mass change and the true reaction temperature and allow us to determine the presence of ongoing thermo-oxidative reactions.

\section{Results and Discussion}

Spherical granules of titanium hydride have microcracks of $20-30 \mathrm{~nm}$ on the surface (Figure 1a). These defects of the surface layer are formed as a result of the occurrence of internal stresses associated with the difference in the rate of hydrogen adsorption on the surface of the granules and the rate of its diffusion into titanium metal particles. The data presented for mapping of the structure of the initial spherical granules of titanium hydride by the chemical composition and energy dispersion spectrum at different points (Figures $1 \mathrm{~b}, 2$ and 3 ) indicate the presence of mainly titanium ions in the surface layer without foreign impurities. 


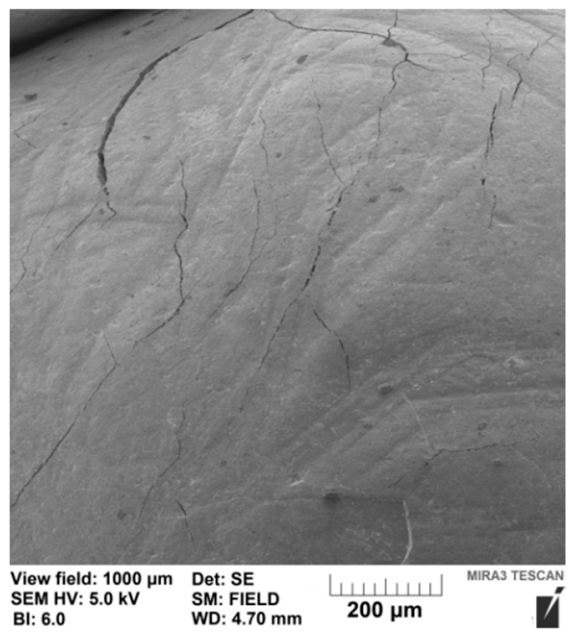

(a)

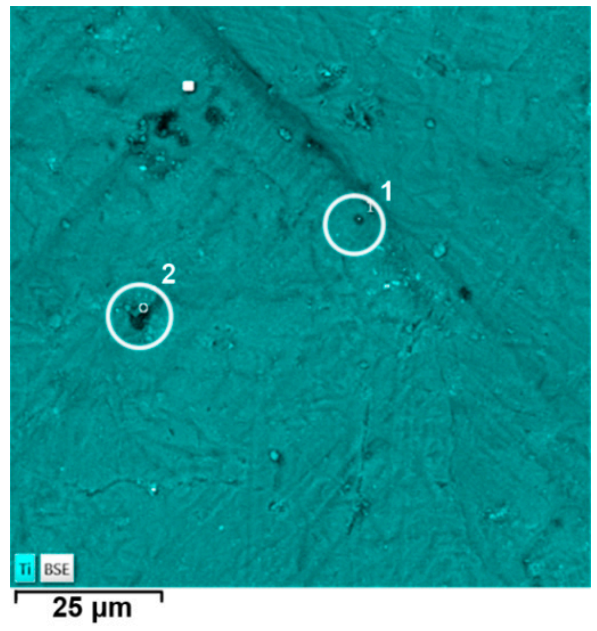

(b)

Figure 1. Micrograph of the surface (a) and mapping the structure (b) of the initial fraction of titanium hydride by chemical composition: 1, 2-zones of mapping of chemical elements.

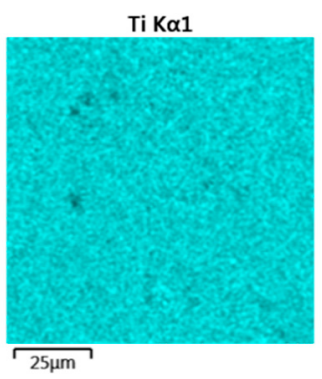

(a)

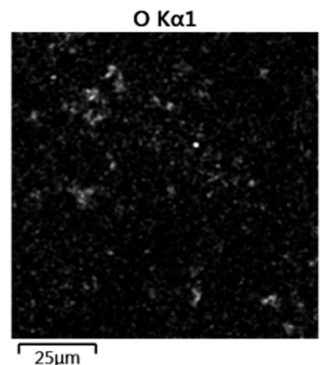

(b)

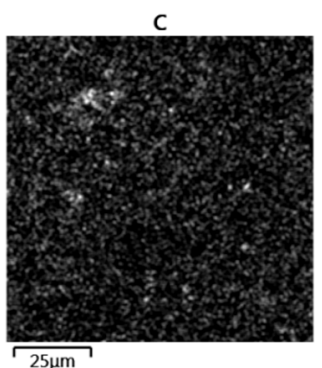

(c)

Figure 2. Legend of mapping the chemical elements $\mathrm{Ti}(\mathbf{a}), \mathrm{O}(\mathbf{b})$, and $\mathrm{C}(\mathbf{c})$ of the initial fraction of titanium hydride.

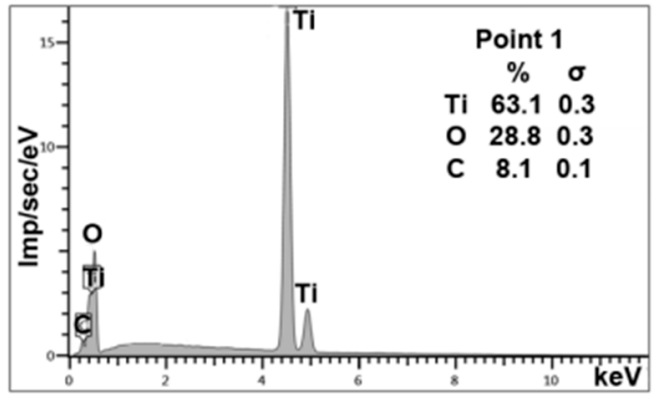

(a)

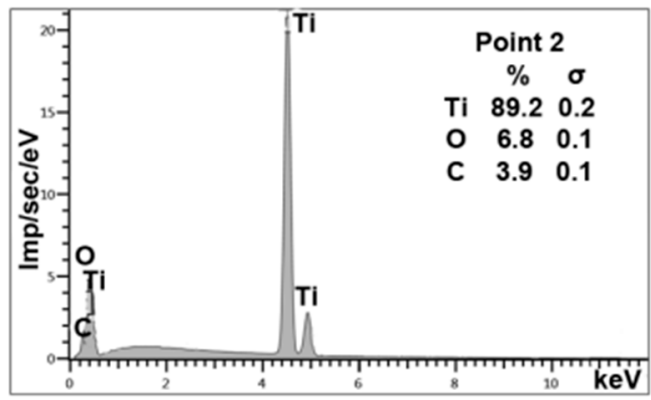

(b)

Figure 3. Energy dispersive spectra at different points of the initial fraction of titanium hydride ((a)—point 1, (b)—point 2).

The analysis of images of the microstructure of the surface of spherical titanium hydride granules modified under dynamic conditions at $\mathrm{pH}=4-5$ (Figure 4) showed that the surface of titanium hydride granules is completely covered with an adsorption layer with a pronounced aggregate-like relief. The resulting coating consists of fused plates and rods (diameter up to $0.7 \mu \mathrm{m}$, length more than $2 \mu \mathrm{m}$ ). The exact dimensions of the plates are difficult to determine, since they are tightly fused with the rods. Comparing the data obtained with the literature $[15,17]$, it can be assumed that the aggregate-like relief is formed as a result of the adsorption of various titanium ions: $\mathrm{Ti}(\mathrm{OH})_{2}{ }^{2+}$ and 
$\left[\mathrm{Ti}\left(\mathrm{H}_{2} \mathrm{O}\right)_{6}\right]^{4+}$. A micrograph with a view field of $1000 \mu \mathrm{m}$ of modified spherical titanium hydride (Figure 4) shows that there are no defects in the form of cracks and depressions characteristic of unmodified titanium hydride granules (Figure 1).
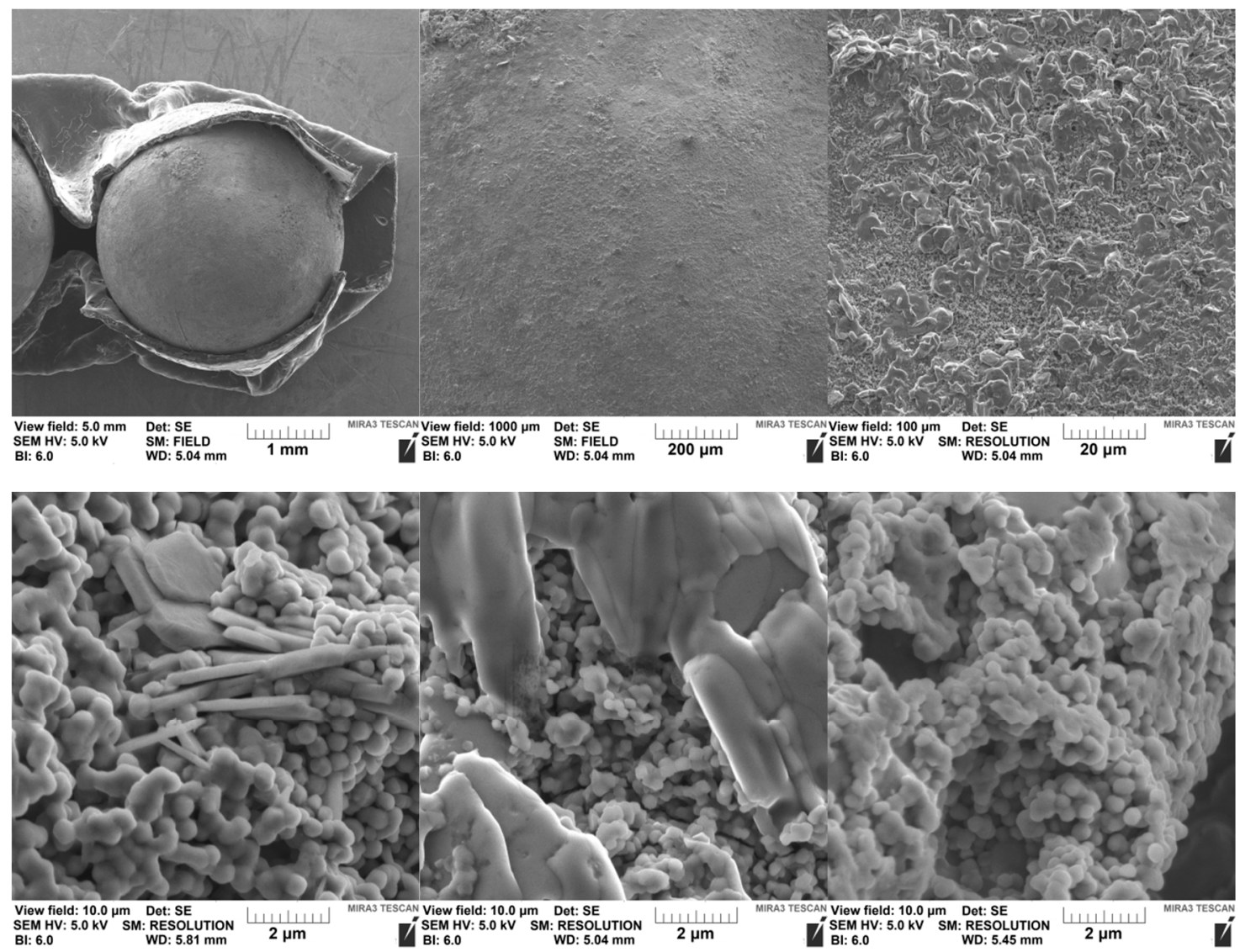

Figure 4. Micrographs of the surface of the titanium hydride shot modified under dynamic conditions in the presence of $\mathrm{NH}_{4} \mathrm{OH}(\mathrm{pH}=4-5)$.

The data shown on the map of the distribution of chemical elements on the surface of the modified spherical titanium hydride granules (Figure 5a) and the energy-dispersion spectra (Figures $5 b, c$ and 6 ) confirm the adsorption of titanium sulfate salts on the surface of the fraction. On the EDS surface of modified spherical titanium (Figure $5 b, c)$, there are peaks showing the content of $\mathrm{S}$ and $\mathrm{O}$ ions; at the same time, the intensity of Ti ions is less than on the EDS of non-modified granules (Figure 3).

Taking into account the methodology of the adsorption experiment described above, it is important to note the absence of desorption during the washing of modified granules with distilled water. This moment indicates a high degree of adhesion of adsorbed ions due to the inclusion of atoms in the crystal lattice of titanium hydride.

According to the parameters presented in Figures 7 and 8, it is possible to judge the degree of surface roughness of the studied samples of spherical granules of titanium hydride before and after adsorption modification. The analysis of the statistical parameters of the surface shows that the initial surface of the titanium hydride fraction is rather rough; there are depressions and protrusions, and the average roughness is $\mathrm{Ra}=16.09 \mathrm{~nm}$ (Figure 7). The roughness parameters of the titanium hydride fraction after treatment with $\mathrm{NH}_{4} \mathrm{OH}(\mathrm{Ra}=2.35 \mathrm{~nm})$ become smoother, which is associated with adsorbed titanium salts (Figure 8). 


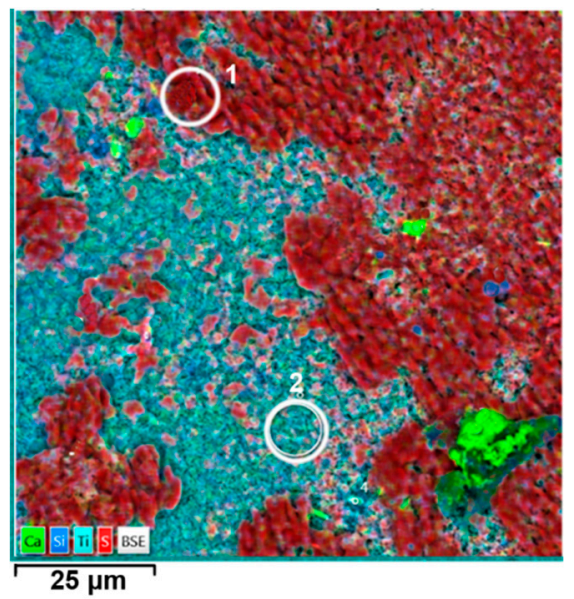

(a)

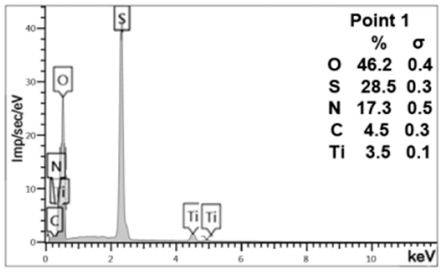

(b)

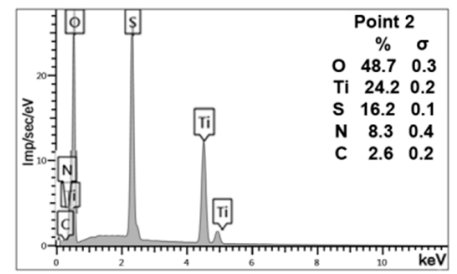

(c)

Figure 5. Structure mapping (a) and energy dispersive spectrum at different points (points (b) - 1 , (c) - 2) of the modified fraction of titanium hydride under dynamic conditions in the presence of $\mathrm{NH}_{4} \mathrm{OH}(\mathrm{pH}=4-5)$.

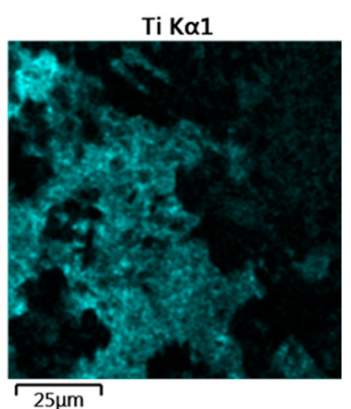

(a)

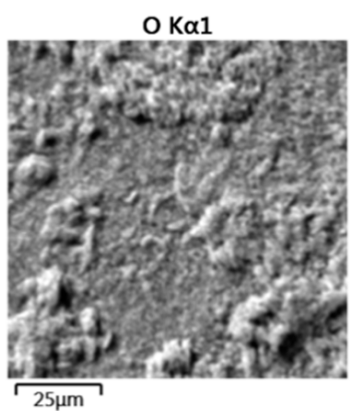

(b)

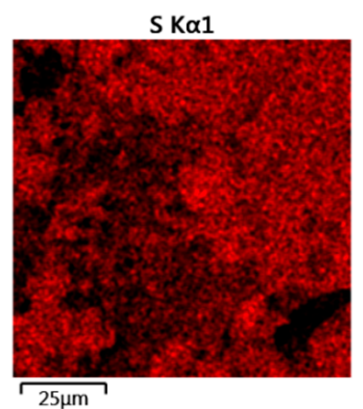

(c)

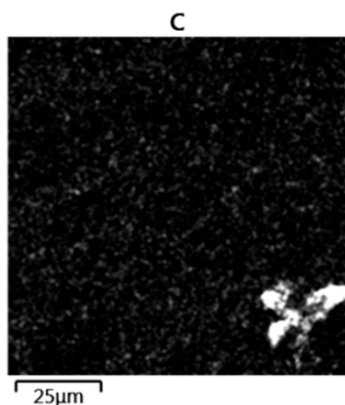

(d)

Figure 6. Legend of mapping the chemical elements $\mathrm{Ti}(\mathbf{a}), \mathrm{O}(\mathbf{b}), \mathrm{S}(\mathbf{c})$, and $\mathrm{C}(\mathbf{d})$ of a modified fraction of titanium hydride under dynamic conditions in the presence of $\mathrm{NH}_{4} \mathrm{OH}(\mathrm{pH}=4-5)$.

The presented data indicate a high degree of adsorption of titanium salts and healing of surface defects of the titanium hydride fractions.

According to the presented physicochemical studies of the surface of spherical granules of titanium hydride, taking into account the surface hydroxylated in an aqueous solution, the following mechanism of interaction of titanium sulfuric acid salts with the surface of granules with the formation of a chemisorption layer is possible (Figure 9).

Subsequent polymerization of titanyl leads to shielding of the surface of the titanium hydride fraction (Figure 10a). After heat treatment (at $180^{\circ} \mathrm{C}$ ) of the modified titanium hydride fraction, excess hydrated water is removed from the surface layer and hydroxotitanyl is formed (Figure 10b).

At the next stage, the adhesion of the copper coating to the surface of the initial and sorption-modified spherical granules of titanium hydride was studied.

Micrographs of the surface and cleavage (Figure 11) of the spherical titanium hydride granules with a copper layer deposited indicate that the surface of the titanium hydride granules is completely covered, with all surface microcracks closed. The thickness of the copper coating is 10-14 $\mu \mathrm{m}$. However, in some areas, there are gaps between the surface layer of the titanium hydride granule and the copper coating, with a width of $0.4-1.0 \mu \mathrm{m}$, which proves the adhesive interaction is weak. 


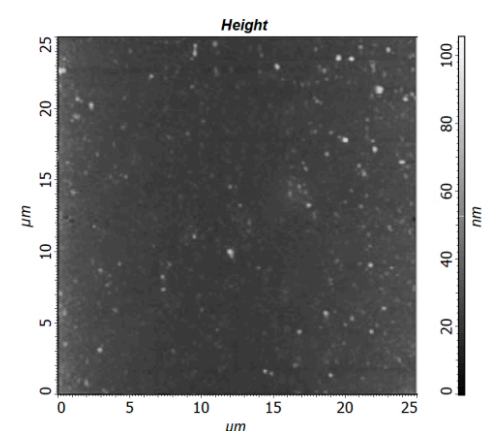

(a)

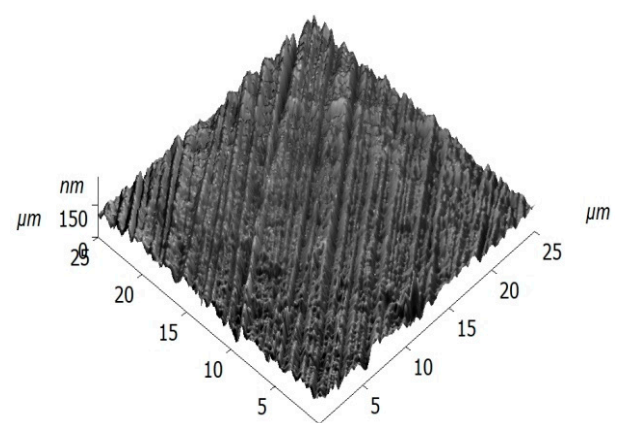

(b)

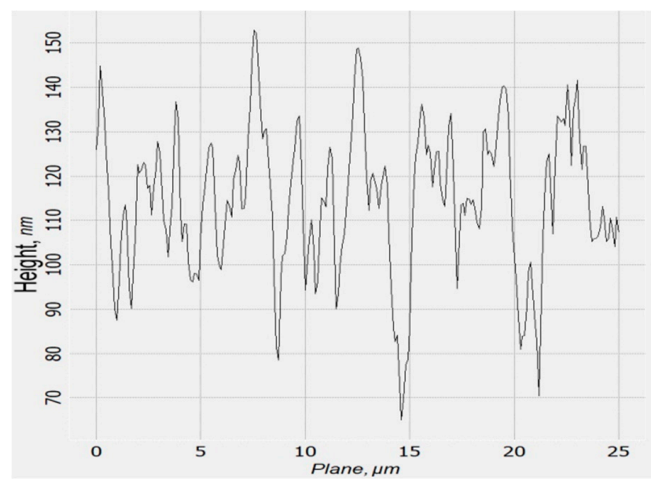

(c)

Figure 7. AFM images of the surface relief of spherical titanium hydride, non-modified: (a) 2D topographic image, (b) 3D topographic image and (c) Surface profile.

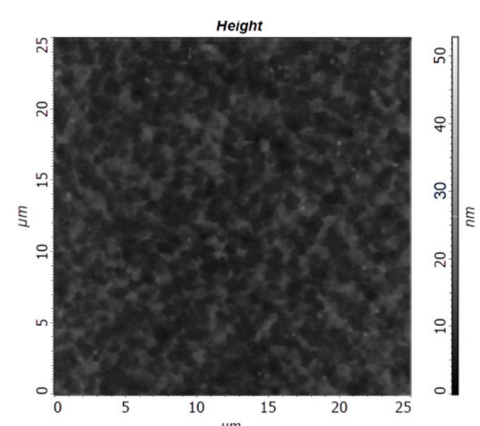

(a)

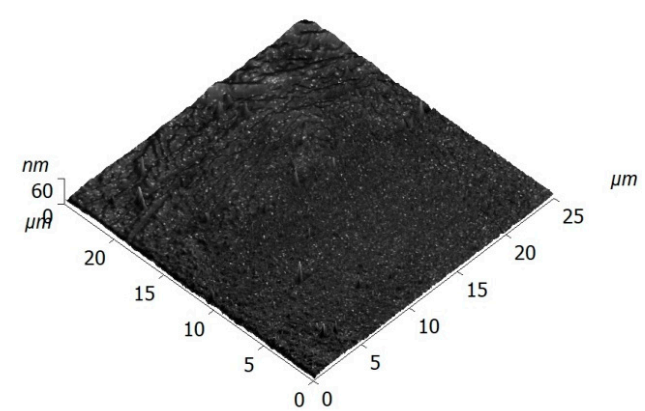

(b)

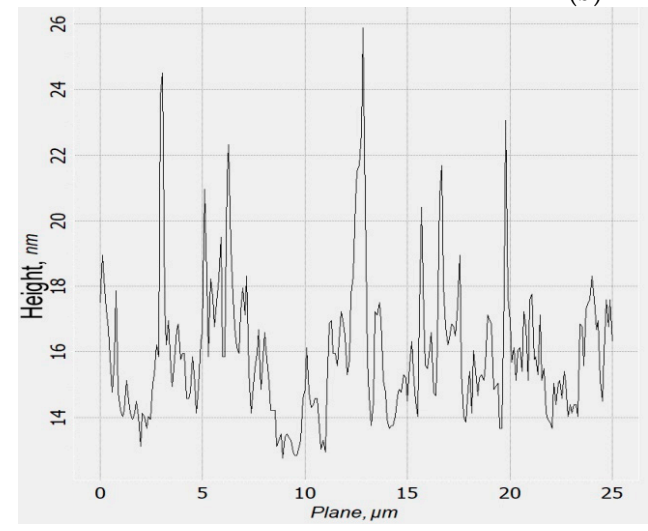

(c)

Figure 8. AFM images of the surface relief of spherical titanium hydride, modified with titanium salts in the presence of $\mathrm{NH}_{4} \mathrm{OH}$ : (a) 2D topographic image, (b) 3D topographic image, and (c) Surface profile. 
$\overbrace{-\mathrm{OH}}+\mathrm{TiOSO}_{4} \stackrel{\mathrm{TiH}_{2} \mathrm{OH}}{\stackrel{\mathrm{HH}_{4} \mathrm{OH}}{\longrightarrow}} \mathrm{TiH}_{2} \lambda_{-\mathrm{OH}}^{\mathrm{OH}}+\mathrm{Ti}_{(\mathrm{OH})_{2} \mathrm{SO}_{4}} \underset{\mathrm{H}_{2} \mathrm{O}}{\longrightarrow}$

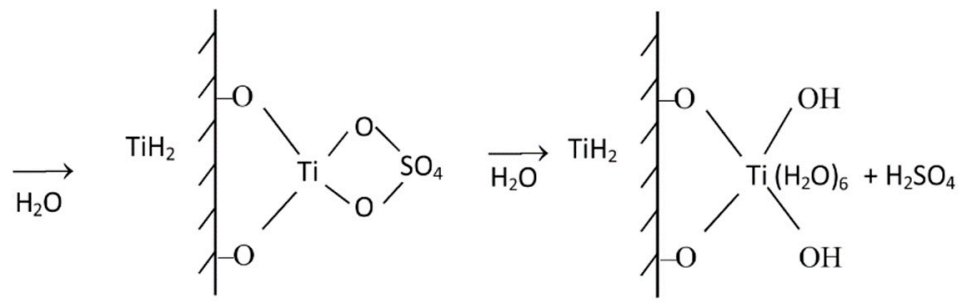

Figure 9. Mechanism of interaction of titanium sulfuric acid salts with the shot surface.

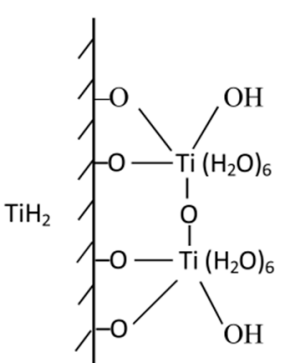

(a)

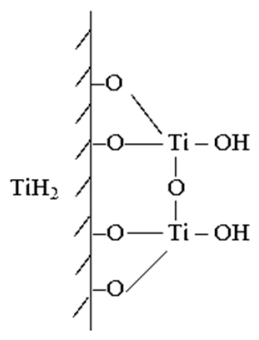

(b)

Figure 10. Screening of the titanium hydride (a) shot surface and formation of hydroxotitanyl (b) on the surface.

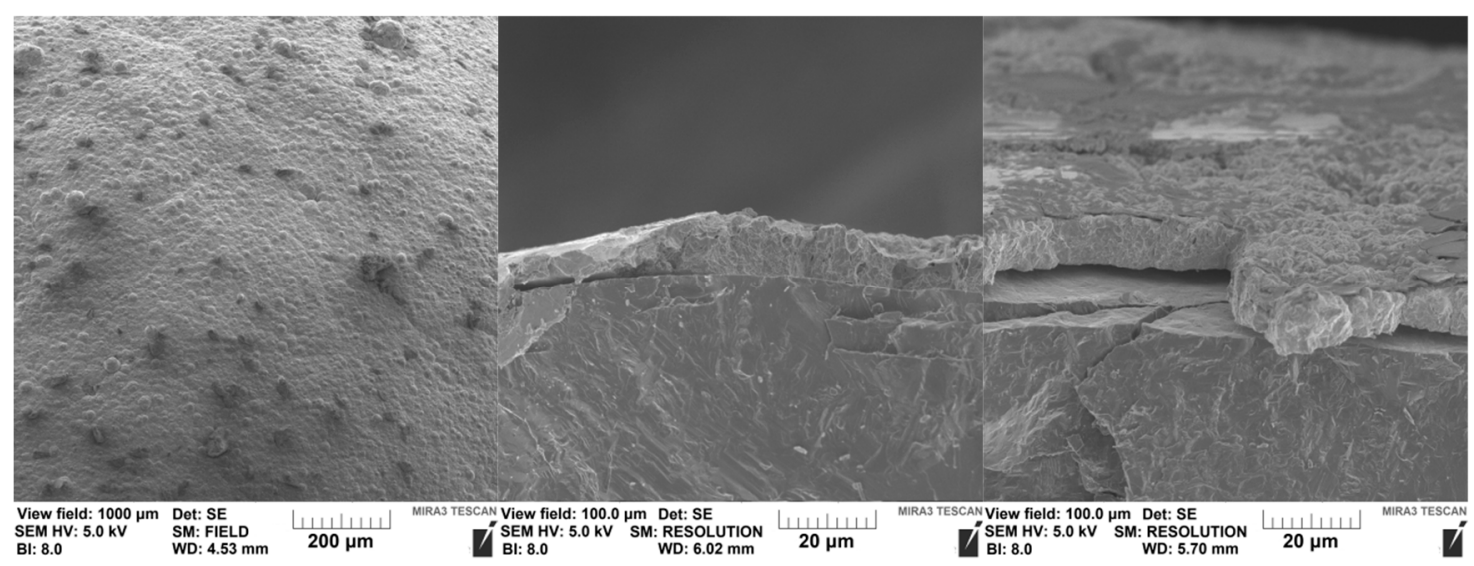

Figure 11. Micrographs of the surface and cleavage of spherical titanium hydride granules modified by copper electrochemical deposition.

Figure 12 shows the microstructure of a multilayer coating on the surface of a spherical titanium hydride granule. To create a multilayer coating, electrochemical deposition of a copper coating on the surface of a titanium hydride granule previously modified by chemisorption under dynamic conditions at $\mathrm{pH}=4-5$ was performed. 

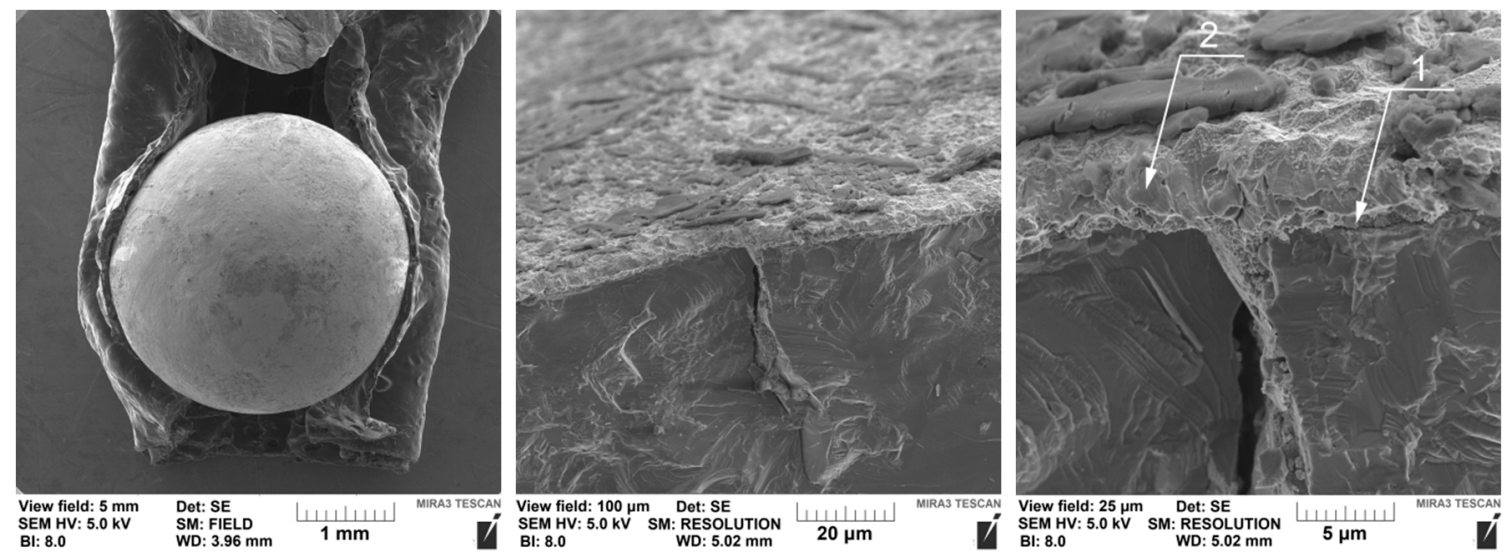

Figure 12. Micrographs of a multilayer coating on the surface of a titanium hydride shot: 1—chemisorption layer, 2-copper layer.

A chemisorbed layer of hydroxotitanyl with a thickness of $\sim 1 \mu \mathrm{m}$ evenly covers the surface of a spherical titanium hydride granule, penetrating into the microcracks. The copper shell has a homogeneous structure with high adhesion to the modified surface of the granules and a weakly defined interface. The thickness of the copper coating is almost the same on the entire surface and averages $\sim 8-10 \mu \mathrm{m}$ (Figure 12). The high degree of adhesion of electrochemically deposited copper on the modified surface of titanium hydride is apparently due to the interaction of partially hydrolyzed copper ions with hydroxotitanyl according to the scheme in Figure 13.

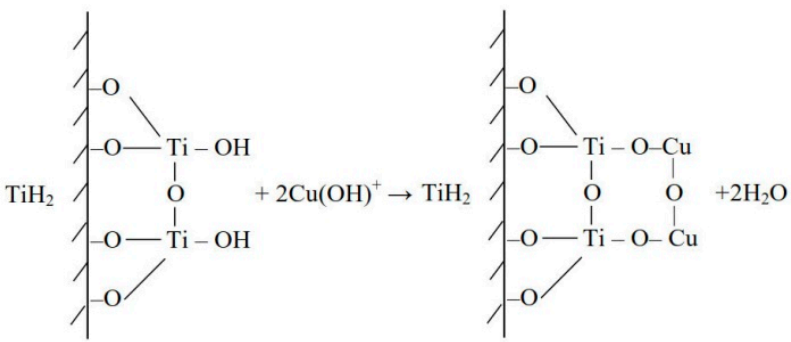

Figure 13. Scheme of interaction of partially hydrolyzed copper ions with hydroxotitanyl during thermal drying.

The conducted studies prove the possibility of creating a multilayer shell of a titaniumcopper coating $\equiv \mathrm{Ti}-\mathrm{O}-\mathrm{Cu}$ - with a total thickness of $\sim 9-11 \mu \mathrm{m}$ on the surface of spherical granules of titanium hydride.

To assess the feasibility of creating a multilayer titanium-copper shell, studies of the heat resistance of unmodified and modified spherical granules of titanium hydride were carried out. Thermogravimetric curves of the DTA of the spherical titanium hydride granules having a multilayer titanium-copper shell (Figure 14b) as well unmodified granules (Figure 14a) are characterized by an insignificant endothermic effect in the range of $100-120^{\circ} \mathrm{C}$ caused by the removal of sorption water. The peak of the endothermic effect corresponding to the maximum decomposition rate of the hydride phase is observed at temperatures of $557.7^{\circ} \mathrm{C}$ for the initial granules (Figure $14 \mathrm{a}$ ) and $784.3^{\circ} \mathrm{C}$ for the modified ones (Figure 14b). The initial and final stages of dehydrogenation of modified titanium hydride correspond to temperatures of $699.7^{\circ} \mathrm{C}$ and $848.6^{\circ} \mathrm{C}$, while for unmodified granules, the temperatures are $462.9^{\circ} \mathrm{C}$ and $722.8^{\circ} \mathrm{C}$. 


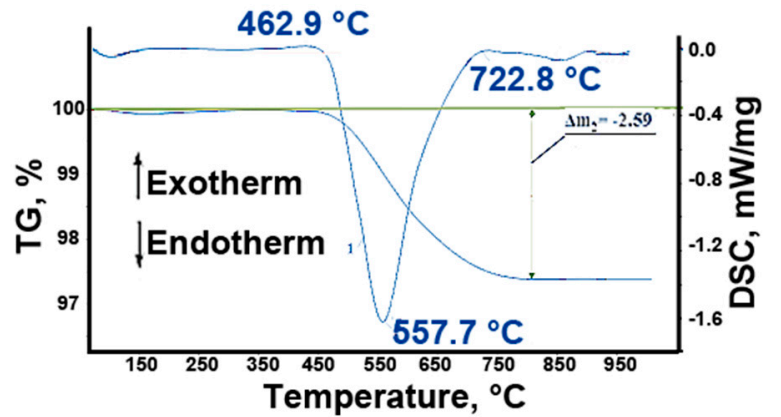

(a)

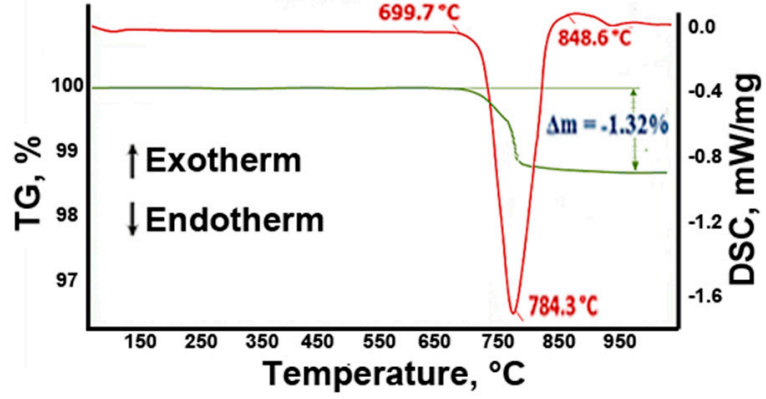

(b)

Figure 14. Dependence of TG and DSC on the temperature of unmodified (a) and modified (b) spherical granules of titanium hydride.

Thus, the modification of the spherical granules of titanium hydride by creating a multilayer titanium-copper shell shifts the beginning of the processes of thermal diffusion of hydrogen to a higher temperature region by $236.8^{\circ} \mathrm{C}$, which proves there is an increase in their thermal stability.

\section{Conclusions}

To increase the thermal stability of titanium hydride, a promising direction is to create a modified sorption layer on its surface that prevents the diffusion of hydrogen into the environment.

The creation of a protective shell on the surface of spherical titanium hydride granules by electrolytic deposition of copper ions allows for the formation of a layer that completely covers the surface of titanium hydride, covering all surface microcracks. However, in some areas, there are gaps $(0.4-1.0 \mu \mathrm{m})$ between the surface layer of the titanium hydride granule and the copper coating, which proves that the adhesive interaction is weak.

To increase the adherence between the titanium hydride substrate and the copper coating, it is necessary to pre-activate the surface by creating an additional layer containing chemically active groups. The surface of the titanium hydride shot after chemical interaction with titanium sulfate salts at $\mathrm{pH}=4-5$ under dynamic conditions is covered with a uniform sorption layer. As a result of subsequent thermal drying at a temperature of $180{ }^{\circ} \mathrm{C}$, excess hydrated water is removed. As a result, the surface of the titanium hydride fraction is completely covered with an adsorption layer of hydroxotitanyl with a pronounced aggregate-like relief. The resulting chemisorbed layer of hydroxotitanyl contributes to the creation of a multilayer shell of a titanium-copper coating on the surface of the spherical titanium hydride granules ( $\equiv \mathrm{Ti}-\mathrm{O}-\mathrm{Cu}$-) with a high adhesive interaction.

The creation of a multilayer titanium-copper shell on the surface of spherical titanium hydride granules increases the thermal stability of the hydride phase by $236.8^{\circ} \mathrm{C}$; the initial dehydrogenation temperature of the unmodified fraction is $462.9^{\circ} \mathrm{C}$, and the modified fraction is $699.7^{\circ} \mathrm{C}$.

Author Contributions: Conceptualization, V.I.P. and R.N.Y.; methodology, V.I.P. and R.N.Y.; validation, V.I.P., R.N.Y. and A.I.G.; investigation, A.I.G.; resources, N.I.C.; data curation, N.I.C.; writingreview and editing, A.I.G. and A.A.K.; visualization, A.A.K.; supervision, N.I.C.; project administration, V.I.P.; funding acquisition, V.I.P. All authors have read and agreed to the published version of the manuscript.

Funding: This work was realized using the equipment of the High Technology Center at BSTU named after V.G. Shukhov and the framework of the State Assignment of the Ministry of Education and Science of the Russian Federation, project № FZWN-2020-0011. 
Conflicts of Interest: The authors declare no conflict of interest. The funders had no role in the design of the study; in the collection, analyses, or interpretation of data; in the writing of the manuscript; or in the decision to publish the results.

\section{References}

1. Matyukhin, P.V. The choice of iron-containing filling for composite radioprotective material. IOP Conf. Ser. Mater. Sci. Eng. 2018, 327, 032036. [CrossRef]

2. Yastrebinsky, R.N.; Karnauhov, A.A.; Yastrebinskaya, A.V. Prospects for the use of neutron-shielding metal hydride materials in the construction of NPP power units. In Proceedings of the International Conference Industrial and Civil Construction, Belgorod, Russia, 18-19 January 2021; Volume 147, pp. 161-167. [CrossRef]

3. Pavlenko, V.I.; Edamenko, O.D.; Cherkashina, N.I.; Kuprieva, O.V.; Noskov, A.V. Study of the attenuation coefficients of photon and neutron beams passing through titanium hydride. J. Surf. Investig. 2015, 9, 546-549. [CrossRef]

4. Smithson, H.; Marianetti, C.A.; Morgan, D.; Van Der Ven, A.; Predith, A.; Ceder, G. First-principles study of the stability and electronic structure of metal hydrides. Phys. Rev. B Condens. Matter Mater. Phys. 2002, 66, 144107. [CrossRef]

5. Yastrebinsky, R.N.; Karnauhov, A.A.; Yastrebinskaya, A.V. Improving the radiation-thermal stability of titanium hydride. J. Phys. Conf. Ser. 2020, 1515, 022002. [CrossRef]

6. Cheng, Y.; Song, S.; Ma, H.; Su, J.; Han, T.; Shen, Z.; Meng, X. Hybrid H2/Ti dust explosion hazards during the production of metal hydride $\mathrm{TiH}_{2}$ in a closed vessel. Int. J. Hydrogen Energy 2019, 44, 11145-11152. [CrossRef]

7. Cheng, Y.; Wu, H.; Liu, R.; Yao, Y.; Su, J.; Wang, W.; Shu, C. Combustion behaviors and explosibility of suspended metal hydride TiH2 dust. Int. J. Hydrogen Energy 2020, 45, 12216-12224. [CrossRef]

8. Liu, X.; Guo, Z.; Ma, C.; Sheng, Y.; Yang, F. Study on preparing spherical nickel coated titanium powders by electroless plating and radio-frequency plasma. In Proceedings of the Ti 2011-the 12th World Conference on Titanium, Beijing, China, 19-24 June 2011; Volume 3, pp. 2220-2222.

9. Wang, J.-J.; Hao, J.-J.; Guo, Z.-M.; Wang, Y.-M. Preparation of spherical tungsten and titanium powders by RF induction plasma processing. Rare Met. 2014, 34, 431-435. [CrossRef]

10. Yang, S.; Gwak, J.-N.; Lim, T.-S.; Kim, Y.-J.; Yun, J.-Y. Preparation of Spherical Titanium Powders from Polygonal Titanium Hydride Powders by Radio Frequency Plasma Treatment. Mater. Trans. 2013, 54, 2313-2316. [CrossRef]

11. Wu, X.-L.; Xu, S.; Pang, A.-M.; Cao, W.-G.; Liu, D.-B.; Zhu, X.-Y.; Xu, F.-Y.; Wang, X. Hazard evaluation of ignition sensitivity and explosion severity for three typical MH2 (M= Mg, Ti, Zr) of energetic materials. Def. Technol. 2020, 17, 1262-1268. [CrossRef]

12. Chen, T.; Yang, C.; Liu, Z.; Ma, H.; Kang, L.; Wang, Z.; Zhang, W.; Li, D.; Li, N.; Li, Y. Revealing dehydrogenation effect and resultant densification mechanism during pressureless sintering of $\mathrm{TiH}_{2}$ powder. J. Alloys Compd. 2021, 873, 159792. [CrossRef]

13. Cao, J.; Xiao, P.; Dai, K.; Li, C.; Zhang, X. Thermal dehydrogenation behavior of $\mathrm{TiH}_{2}$ and its dynamics calculation. Zhongguo Youse Jinshu Xuebao Chin. J. Nonferrous Met. 2014, 24, 733-738.

14. Guo, F.; Jain, A.; Miyaoka, H.; Kojima, Y.; Ichikawa, T. Critical temperature and pressure conditions of degradation during thermochemical hydrogen compression: A case study of V-based hydrogen storage alloy. Energies 2020, 13, 2324. [CrossRef]

15. Chirico, C.; Tsipas, S.A.; Wilczynski, P.; Gordo, E. Beta Titanium Alloys Produced from Titanium Hydride: Effect of Alloying Elements on Titanium Hydride Decomposition. Metals 2020, 10, 682. [CrossRef]

16. Gao, H.; Shi, R.; Zhu, J.; Liu, Y.; Shao, Y.; Zhu, Y.; Zhang, J.; Li, L.; Hu, X. Interface effect in sandwich like Ni/Ti3C2 catalysts on hydrogen storage performance of $\mathrm{MgH}_{2}$. Appl. Surf. Sci. 2021, 564, 150302. [CrossRef]

17. Gkomoza, P.; Lampropoulos, G.; Vardavoulias, M.; Pantelis, D.; Karakizis, P.; Sarafoglou, C. Microstructural investigation of porous titanium coatings, produced by thermal spraying techniques, using plasma atomization and hydride-dehydride powders, for orthopedic implants. Surf. Coatings Technol. 2018, 357, 947-956. [CrossRef]

18. Hu, G.; Chen, Y.; Wang, M.; Liu, B.; Yan, S. Thermal control technology for the space station adjoint modular satellite based on new thermal control materials. IOP Conf. Ser. Mater. Sci. Eng. 2020, 793, 012031. [CrossRef]

19. Ko, W.-S.; Park, K.B.; Park, H.-K. Density functional theory study on the role of ternary alloying elements in TiFe-based hydrogen storage alloys. J. Mater. Sci. Technol. 2021, 92, 148-158. [CrossRef]

20. Krotov, D.M. Possibilities and problems of using MIM technology in manufacturing parts of aircraft elements made of titanium and titanium alloys. AIP Conf. Proc. 2021, 2318, 020002. [CrossRef]

21. Liu, T.; Chen, C.; Wang, F.; Li, X. Enhanced hydrogen storage properties of magnesium by the synergic catalytic effect of TiH1.971 and TiH1.5 nanoparticles at room temperature. J. Power Sources 2014, 267, 69-77. [CrossRef]

22. Senkevich, K.; Pozhoga, O. Experimental Investigation of hydrogen absorption by commercial high alloyed Ti2AlNb-based alloy in cast and rapidly solidified state. Vacuum 2021, 191, 110379. [CrossRef]

23. Sickafus, K.E.; Grimes, R.W.; Valdez, J.A.; Cleave, A.; Tang, M.; Ishimaru, M.; Corish, S.M.; Stanek, C.R.; Uberuaga, B. Radiationinduced amorphization resistance and radiation tolerance in structurally related oxides. Nat. Mater. 2007, 6, 217-223. [CrossRef] [PubMed]

24. Young, K.; Ouchi, T.; Huang, B.; Nei, J.; Fetcenko, M. Studies of Ti1.5Zr5.5V0.5(MxNi1-x)9.5 (M=Cr, Mn, Fe, Co, Cu, Al): Part 1. Structural characteristics. J. Alloys Compd. 2010, 501, 236-244. [CrossRef]

25. Zelekew, O.A.; Kuo, D.-H. Facile synthesis of $\mathrm{SiO}_{2} @ \mathrm{Cu}_{\mathrm{x}} \mathrm{O} @ \mathrm{TiO}_{2}$ heterostructures for catalytic reductions of 4-nitrophenol and 2-nitroaniline organic pollutants. Appl. Surf. Sci. 2017, 393, 110-118. [CrossRef] 
26. Akhtar, M.A.; Ilyas, K.; Dlouhý, I.; Siska, F.; Boccaccini, A.R. Electrophoretic Deposition of Copper(II)—Chitosan Complexes for Antibacterial Coatings. Int. J. Mol. Sci. 2020, 21, 2637. [CrossRef]

27. Ide, T.; Tsunemi, A.; Nakajima, H. Fabrication of Porous Copper with Directional Pores by Continuous Casting Technique Through Thermal Decomposition of Hydride. Met. Mater. Trans. A 2014, 45, 1418-1424. [CrossRef]

28. Sahu, K.; Bisht, A.; Khan, S.A.; Pandey, A.; Mohapatra, S. Engineering of morphological, optical, structural, photocatalytic and catalytic properties of nanostructured $\mathrm{CuO}$ thin films fabricated by reactive DC magnetron sputtering. Ceram. Int. 2019, 46, 7499-7509. [CrossRef]

29. Shehayeb, S.; Deschanels, X.; Ghannam, L.; Karame, I.; Toquer, G. Tandem selective photothermal absorbers based on EPD of $\mathrm{CuO}$ colloidal suspension coupled with dip-coated silica. Surf. Coatings Technol. 2021, 408, 126818. [CrossRef]

30. Kucheryavyi, O.V.; Bratanich, T.I.; Skorokhod, V.V.; Kopylova, L.I.; Krapivka, N.A. Structural and phase mechanism and rate of interaction between $\mathrm{TiCu}_{1} \mathrm{Ti}_{3} \mathrm{Cu}_{4}$, and $\mathrm{Ti}_{2} \mathrm{Cu}_{3}$ intermetallic compounds and hydrogen. I. Formation and decomposition of intermetallic hydrides. Powder Met. Met. Ceram. 2012, 51, 234-242. [CrossRef]

31. Nakajima, H.; Ide, T. Fabrication of Porous Copper with Directional Pores through Thermal Decomposition of Compounds. Met. Mater. Trans. A 2008, 39, 390-394. [CrossRef]

32. Han, T.; Li, J.; Zhao, N.; He, C. Microstructure and properties of copper coated graphene nanoplates reinforced Al matrix composites developed by low temperature ball milling. Carbon 2019, 159, 311-323. [CrossRef]

33. Semboshi, S.; Yamauchi, S.; Numakura, H. Formation of Titanium Hydride in Dilute Cu-Ti Alloy by Aging in Hydrogen Atmosphere and Its Effects on Electrical and Mechanical Properties. J. Jpn. Inst. Met. 2012, 76, 496-503. [CrossRef]

34. Zhou, C.; Bowman, R.C.; Fang, Z.Z.; Lu, J.; Xu, L.; Sun, P.; Liu, H.; Wu, H.; Liu, Y. Amorphous TiCu-Based Additives for Improving Hydrogen Storage Properties of Magnesium Hydride. ACS Appl. Mater. Interfaces 2019, 11, 38868-38879. [CrossRef]

35. Pronichev, D.; Gurevich, L.M.; Trykov, Y.P.; Trunov, M.D. Investigation of aluminum-copper bimetal-based intermetallide coating produced by contact melting method. Inorg. Mater. Appl. Res. 2016, 7, 97-101. [CrossRef]

36. Semboshi, S.; Nishida, T.; Numakura, H. Microstructure and mechanical properties of $\mathrm{Cu}-3$ at.\% Ti alloy aged in a hydrogen atmosphere. Mater. Sci. Eng. A 2009, 517, 105-113. [CrossRef]

37. Wu, H.; Zheng, Z.; Toe, C.Y.; Wen, X.; Hart, J.N.; Amal, R.; Ng, Y.H. A pulse electrodeposited amorphous tunnel layer stabilises $\mathrm{Cu}_{2} \mathrm{O}$ for efficient photoelectrochemical water splitting under visible-light irradiation. J. Mater. Chem. A 2020, 8, 5638-5646. [CrossRef]

38. Zhao, H.; Guo, F.; Zhu, L.; He, J.; Yin, F. The effect of $\mathrm{Cu}$ addition on the crystallization behavior and tribological properties of reactive plasma sprayed TiCN-Cu coatings. Ceram. Int. 2019, 46, 8344-8351. [CrossRef] 